\title{
Health disorders related to learning the welding trade: assessment of approaches to risk communication ${ }^{1}$
}

\author{
Clarice Alves Bonow ${ }^{2}$ \\ Marta Regina Cezar-Vaz ${ }^{3}$ \\ Lauro Roberto Witt da Silva ${ }^{4}$ \\ Laurelize Pereira Rocha ${ }^{5}$ \\ Claudia Turik ${ }^{6}$
}

\begin{abstract}
Objective: to assess the identification of health disorders as self-reported by apprentices of welding and to analyze the strength of the relationship between age and time of experience with self-reported health disorders before and after a socio-environmental nursing intervention. Method: this quasi-experimental, non-randomized, before-and-after study was conducted with 86 welding apprentices from a private entity. Results: the results show a significant difference for the pre- and post-test means and an increase in the post-test mean score for the cardiovascular, respiratory and cutaneous systems. There was also a negative correlation between the apprentices' ages and the identification of health disorders. Conclusion: the socio-environmental nursing intervention enabled obtaining information on health disorders related to welding. In turn, such information enabled the apprentices to assess information and self-report health disorders.
\end{abstract}

Descriptors: Welding; Occupational Risks; Occupational Diseases; Occupational Health Nursing; Health Communication.

\footnotetext{
${ }^{1}$ Paper extracted from doctoral dissertation "Perception and risk communication: assessment of nursing environmental intervention on process of training welders", presentd to Escola de Enfermagem, Universidade Federal do Rio Grande, Rio Grande, RS, Brazil.

2 PhD, Assistant Professor, Universidade Federal do Pampa, Uruguaiana, RS, Brazil.

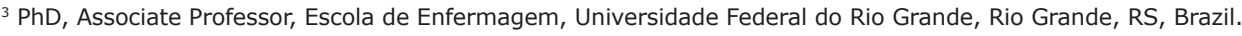

${ }^{4}$ PhD, Adjunct Professor, Escola de Engenharia, Universidade Federal do Rio Grande, Rio Grande, RS, Brazil.

${ }^{5}$ Doctoral student, Escola de Enfermagem, Universidade Federal do Rio Grande, Rio Grande, RS, Brazil.

${ }^{6}$ MSc, Professor, Instituto Federal de Educação Ciência e Tecnologia, Rio Grande, Rio Grande, RS, Brazil.
}

Corresponding Author:

Clarice Alves Bonow

Rua XV de Novembro, 1600

Centro

CEP: 97501-570, Uruguaiana, RS, Brasil

E-mail: claricebonow@unipampa.edu.br
Copyright (c) 2014 Revista Latino-Americana de Enfermagem This is an Open Access article distributed under the terms of the Creative Commons Attribution Non-Commercial License (CC BY-NC).

This license lets others distribute, remix, tweak, and build upon your work non-commercially, and although their new works must also acknowledge you and be non-commercial, they don't have to license their derivative works on the same terms. 


\section{Introduction}

Welding is an operation that aims to obtain coalescence produced by localized heating to an appropriate temperature with or without the application of pressure or filler metal(1). The subject involving health disorders affecting welders has been researched in different countries such as the United States ${ }^{(2-3)}$, Italy(4), France $^{(5)}$, Denmark(6), Ecuador(7), Sweden(8), Spain( ${ }^{(9)}$, India(10), and Brazil(11).

Welders are exposed to diverse risk factors during work, such as physical, chemical and physiological risks ${ }^{(12)}$. Exposure to these factors may trigger different health disorders. There are studies addressing some of the health disorders that may be triggered due to welding, such as those investigating skin cancer conducted in the United States(2), Italy(3), and France(5). There is also a concern in the United States with coronary diseases $^{(3)}$; in Denmark ${ }^{(6)}$ the focus is on lung disorders; researchers in Spain focus on stomach $\operatorname{cancer}^{(9)}$; and studies conducted in Ecuador ${ }^{(7)}$ and Sweden ${ }^{(8)}$ address work-related musculoskeletal disorders (WMSDs)(7), while noise-induced hearing loss (NIHL) is mainly studied in India(10) and Brazil(11).

Physical risk factors to which welders are exposed include noise that originates from welding machines and non-ionizing radiation that originates from the opening of the welding arc. Such factors can trigger disorders related to the auditory ${ }^{(10-11)}$ system and to the cutaneous system, such as skin cancer ${ }^{(2,4-5)}$.

Risk factors include chemical contact with different types of metals in solid and gaseous states. Exposure to smoke from the burning of these metals may lead to respiratory disorders. One example of a harmful compound is stainless steel, the smoke of which can cause acute pulmonary injury, while the size of the particles inhaled and the time of exposure to welding are significant factors that should be taken into account when protective measures are developed ${ }^{(13)}$. Another example is exposure to chrome. One cohort study(6) conducted with male welders between 1964 and 1984 identified a greater incidence of lung cancer among those exposed to this metal.

In addition to the respiratory system, exposure to chemical compounds also put workers at risk of disorders in the cardiac system. One investigation conducted with construction workers, including welders, reports a variability in the heart rate during occupational exposure and at night, showing that metal particles inhaled during work have an organic influence, more specifically causing arrhythmias ${ }^{(3)}$. Another system that may be harmed due to chemical risk factors is the gastric system. Welders are professionals at risk of stomach cancer because they work in dusty environments( ${ }^{(9)}$.

The physiological risk factors include incorrect posture while engaged in welding, because workers perform their work on a fixed metal piece. The workers are the ones required to move around the piece to make the weld. Such an occupational characteristic forces workers to remain in incorrect ergonomic postures in order to obtain a better weld. Additionally, excessive vibration from the welding machine is associated with back pain ${ }^{(7)}$.

The city of Rio Grande do Sul (RS) Brazil is known for its intense concentration of activities focused on maritime labor. Specifically, the main purpose of the shipyard, where the dry dock is located in this city, is the construction and repair of oilrigs. From this perspective, welding work is needed for technological development in the market of shipbuilding production. This is a process that leads to conditions that are inappropriate for the health of workers who represent the driving force of the products of welding.

Careful attention is required to produce knowledge able to support healthy working conditions for these workers, because economic conditioners are strong determinants and often harm the health of the human beings included in the productive context. We understand that the educational process occurs before effective practice, and which can induce or direct or enable healthy practices. For this reason, given the needs of the field of welding in this city, coupled with the different risk factors these workers are exposed to, we propose this study's objective to be the welding apprentice in his/her training process.

Nursing, as a field of specific knowledge and as social practice, develops knowledge that consolidates and strengthens itself as a science that produces human health(14) through the use of the formal technology of occupational health, providing innovation with the production of knowledge through healthcare provided to workers. In this sense, it is necessary for occupational nurses to know the particularities of different occupational environments and, within these environments, to develop strategies to change the health conditions of different environments and workers. Studies report the risks and occupational diseases to which workers are exposed in different environments, among them the port environment ${ }^{(15)}$, sugar cane 
cutting $^{(16)}$, and bakeries ${ }^{(17)}$. From this perspective, we suggest that studies addressing occupational health be encouraged as an instrument able to seek improved health. It is believed that such studies contribute to the development of practices aimed to produce health in the delivery of healthcare to workers.

This study's objectives were to assess the identification of health disorders that were selfreported by welding apprentices and analyze the strength of the relationship between age and time of experience with health disorders that are self-reported by apprentices before and after the implementation of a socio-environmental nursing intervention (SENI). In the literature, before- and after-studies addressing welders present an experimental analysis with biological material(18-19). In this study, we sought to innovate through a process of interaction designed to promote healthy practices: risk communication $(R C) . R C$ is understood here as an interactive process of the exchange of information and opinions among individuals, groups and institutions(20). Such a tool helps to promote changes in individual and collective behavior, including public participation and conflict resolution. RC was used as a tool to develop the SENI with welding apprentices.

\section{Method}

This quasi-experimental, non-randomized, beforeand-after study was approved by the Institutional Review Board at the Federal University of Rio Grande do Sul (FURG) (No. 40/2010) and developed in November and December 2011. The intentional non-probabilistic sample was composed of 86 welding apprentices from six classes with approximately 14 apprentices per class in a private entity in the city of Rio Grande do Sul (RS) Brazil. The objective of the study is to promote the development and improvement of the national industry. The entity graduated a total of 432 welding apprentices in 2011. It provides the qualification of professionals and the improvement of products and processes for industries through technical and technological training and services. The welding training program, which the apprentices were attending, included theoretical and practical classes with a four-month duration. The classes in which the SENI was implemented had already initiated the practical welding activities. We note that in order to conduct the study, we needed to attend the welding classes. One of the researchers attended the classes for one year and half before data collection was initiated. The main focus of this lead in-time was to become familiar with the learning process of this specific group.

In addition to the participation of the apprentices, the ISAE also had the participation of six researchers from the Health Studies and Socio-Environmental Processes and Collective Production Laboratory (LAMSA). Six learning and teaching workshops (LTW) were held, each with one class of welding apprentices. The time used for planning was 40 hours and the workshops took four hours each, totaling 24 hours. The LTW took place on the institution's premises in a room used for theoretical activities. This practice is also included in the Health Production in Different Occupational Environments Program (PSSE) of LAMSA at the Federal University of Rio Grande, College of Nursing, Brazil. The PSSE is a set of interconnected and continuous actions with an axis concerning the promotion of socio-environmental health in different work process, in which the environments integrate the studies of the academic group LAMSA.

The socio-environmental nursing intervention was based on the concept of risk communication (20-21). The content (message) was developed based on the nature of risk through the classification of risk factors (physical, chemical and physiological) and potential health disorders due to exposure to these risk factors. The physiological systems were addressed in the socioenvironmental nursing intervention in the following order: cutaneous, respiratory, cardiac, auditory, musculoskeletal, and gastric systems. The anatomicalphysiological characteristics of systems were presented to the apprentices, as well as risk factors present in the practice of welding that harm the systems along with recommendations for promoting the health of welding apprentices.

The SENI followed the following stages: 1 - presentation of the study and research group and signing free and informed consent forms; 2 - completion of pre-test questionnaire; 3 - implementation of the socio-environmental nursing intervention; 4 - completion of the post-test questionnaire (Figure 1). This last stage took place on the last day of the welding training program, approximately one month after the SENI was implemented. During the SENI, we could list the risk factors to which apprentices are exposed and the organic systems that are affected by them. It is important to note that the risk factors were identified in order to explain health disorders, since the relationship among them characterizes the working conditions. 


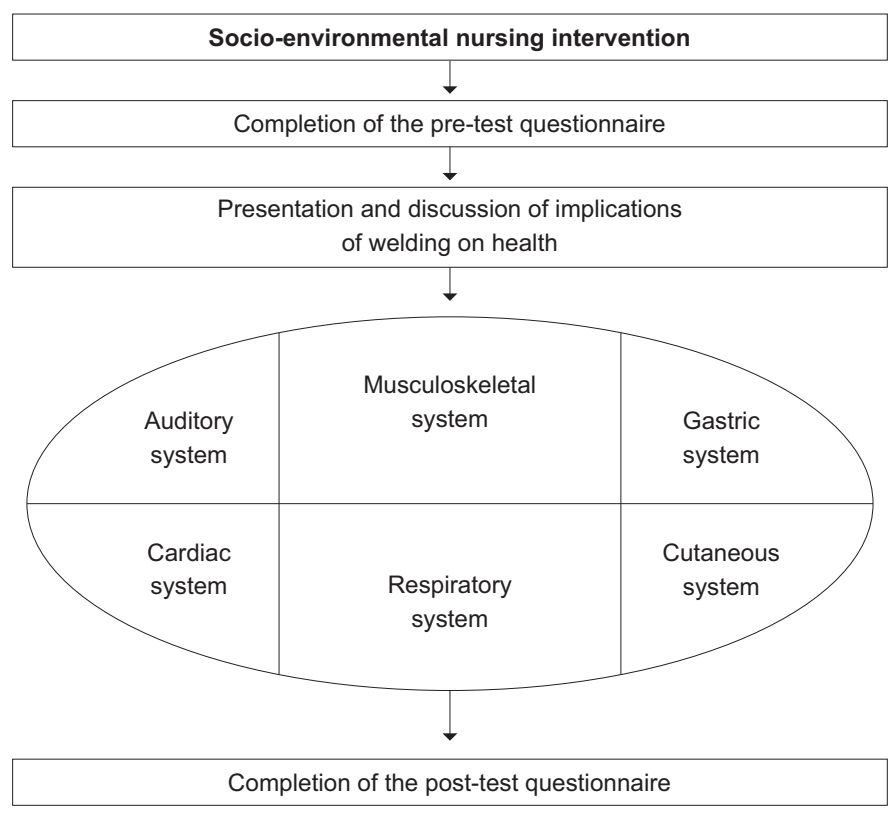

Figure 1 - Stages of the Socio-Environmental Nursing Intervention

The questionnaire addressed socio-demographic variables (age, sex, marital status and schooling) and 41 variables related to the identification of health disorders that involved the musculoskeletal (15 items), cutaneous (12 items), auditory (4 items), gastric (4 items), respiratory (3 items), and cardiovascular (3 items) systems. The answers composed a five-point Likert scale ( $0=$ never feel/felt it; $1=$ almost never feel/ felt it; 2 =sometimes I feel/felt it; 3 =almost always feel/ felt it; $4=$ always feel/felt it). This way, the maximum mean of each block of questions on systems is 4 .

The results obtained were gathered and analyzed using the SPSS version 19.0. Data were presented using percentages, means, and standard deviation ( $\pm S D$ ). Student's t test of significance was used to analyze the apprentices' answers concerning health disorders related to welding for matched samples $(p<0.05)$. Spearman's correlation was used to analyze the strength of the relationship between the variables age and time of experience with health disorders as self-reported by the apprentices before and after the intervention. This test was chosen due to the non-normality of the variables age and time of experience.

\section{Results}

\section{Characterization of participants}

The 86 individuals who participated in the socioenvironmental nursing intervention were aged from 18 to 44 year old (mean age 27.4 years old, SDP= \pm 7.1 );
76.7\% were male; $54.7 \%$ reported being single; $52.3 \%$ had completed high school; $67.4 \%$ had attended welding training provided by companies in the shipbuilding industry in Rio Grande; and $60.5 \%$ had never worked in the field.

\section{Health Disorders in Relation to the Organic Systems as Self-Reported by Welding Apprentices}

Table 1 presents the means $( \pm S D$ ) concerning the organic disorders in the different times of assessment (before, after and the relationship between before and after) of the SENI. The musculoskeletal and cutaneous systems obtained the highest mean scores after the SENI, showing a greater identification of disorders in these systems. In the comparison of means before and after the SENI, we observed that there was an increase in the means of the cardiovascular, musculoskeletal, respiratory and cutaneous systems. This increase of mean scores indicates there was a greater identification of disorders in these systems, even if small, after the intervention. Assessment after the intervention shows a decrease in the mean scores of the hearing and gastric systems, indicating that the welding apprentices referred less to the content (message) transmitted regarding disorders related to these systems.

The Student's $t$ test, used to detect significance when relating differences of means before and after the SENI, indicated a greater difference between the mean scores before and after the intervention for the musculoskeletal system $(p<0.05)$. No statistical differences were found for the remaining systems. 
Table 1 - Mean of identification of organic disorders as self-reported by welding apprentices before and after the Socio-Environmental Nursing Intervention $(n=86)$. Rio Grande, RS, Brazil, 2011

\begin{tabular}{|c|c|c|c|c|c|c|}
\hline \multirow{3}{*}{ Health Disorders } & \multicolumn{5}{|c|}{ Assessment } & \multirow{3}{*}{$\mathbf{p}$} \\
\hline & \multicolumn{2}{|c|}{ Before } & \multicolumn{2}{|c|}{ After } & \multirow{2}{*}{$\begin{array}{c}\text { Before/After } \\
\text { Difference between } \\
\text { means ( } \pm S D \text { ) }\end{array}$} & \\
\hline & $\mathbf{n}$ & $\begin{array}{l}\text { Mean } \\
( \pm D P)\end{array}$ & n & $\begin{array}{l}\text { Mean } \\
( \pm D P)\end{array}$ & & \\
\hline Auditory system & 76 & $0.25(0.39)$ & 76 & $0.22(0.38)$ & $0.02(0.28)$ & 0.423 \\
\hline Cardiovascular system & 78 & $0.08(0.26)$ & 78 & $0.12(0.30)$ & $-0.04(0.23)$ & 0.078 \\
\hline Gastric system & 75 & $0.24(0.46)$ & 75 & $0.23(0.38)$ & $0.00(0.37)$ & 0.938 \\
\hline Musculoskeletal system & 66 & $0.54(0.62)$ & 66 & $0.66(0.63)$ & $-0.11(0.42)$ & 0.029 \\
\hline Respiratory system & 76 & $0.22(0.39)$ & 76 & $0.28(0.44)$ & $-0.06(0.33)$ & 0.092 \\
\hline Cutaneous system & 71 & $0.57(0.54)$ & 71 & $0.59(0.53)$ & $-0.02(0.42)$ & 0.647 \\
\hline
\end{tabular}

Correlation of age, time of experience and organic disorders as self-reported by the welding apprentices revealed a negative correlation between the apprentices' ages, the mean scores after the intervention for the musculoskeletal, respiratory, cardiac $(p<0.05)$ and gastric $(p<0.01)$ systems and the mean scores before and after for the cutaneous $(p<0.01)$ and auditory $(p<0.01 ; p<0.05)$ systems: the younger the individual, the higher the mean during assessment of the systems. Such findings correspond with the nature of disorders (message) and the interaction of communication processed during the intervention.

The pattern is changed when the correlation between organic systems is analyzed, indicating a positive and significant correlation among most of them. Time of experience did not present correlation with any variable, which tends to show that the communication process may influence the welding apprentice, whether he has experience or not.

\section{Discussion}

The means before and after the SENI were higher for the health disorders related to the musculoskeletal and cutaneous disorders, which indicates that the apprentices more frequently identified health disorders in these systems in relation to the practice of welding. We note that the musculoskeletal system presented significant differences on the Student's $t$ test for matched samples. These findings corroborate studies addressing disorders related to welding, which present welders as a group at risk of musculoskeletal and cutaneous disorders $(2,4-5,7)$. Processed communication concerning the nature of the message (disorders related to organic systems) explained situations that can lead to such disorders. We emphasized that inappropriate postures, repetitive movements and the constant vibration of the welding machine are examples of the wear to which the musculoskeletal system is subject. Most of the activities developed in welding require a variety of movements, such as bending, stretching, or long periods of standing, which requires the one performing the activities to move constantly. When these activities are performed, specific muscle groups are used (back and scapular muscles), resulting in overload and an increased risk of disorders ${ }^{(7)}$. Other workers besides welders can experience organic disorders. Studies addressing organic disorders diagnosed in temporary dockworkers report work-related musculoskeletal diseases ${ }^{(15)}$.

Studies ${ }^{(8,22)}$ have been conducted due to a concern with the manual work performed by welders and the constant vibration of tools used during the welding process. One investigation showed that the use of welding tools exceeds the limits of exposure, when operated for more than eight hours. Knowledge concerning these characteristics of the welding activity was emphasized in the SENI; that is, we stressed that the musculoskeletal disorders may occur due to the requirement of constant physical effort on the part of the apprentices and future workers. Specifically, the significant difference for the musculoskeletal system may be explained by the fact that pain originating from disorders in this system has a multifactorial origin, which may be related to the work itself, the worker's individual characteristics, personality traits, or life history ${ }^{(23)}$. Even though not all the potential factors of this specific disorder were addressed in this study, we find that it was sufficient to promote communication of the nature of such risk and the relationship with organic systems, enabling, in this specific case, knowledge concerning disorders related to the musculoskeletal system. Therefore, the apprentices in the pre-test identified the association; however, this association was greater after the intervention because they identified how much welding is related to disorders in the musculoskeletal system. 
The nature of the cutaneous system and its potential disorders were recognized after communication was accomplished through the intervention (SENI). It is known that the welder's cutaneous system is mainly exposed to ultraviolet radiation (UV) that originates from the opening of the electric arc during welding. Occupational exposure to UV increases the risk of skin cancer $^{(4)}$. Studies reinforce the communication developed with the apprentices in this study concerning the nature of risk and organic disorders as a result of exposure to this occupation's risk factors. One example is presented in a case study ${ }^{(2)}$ reporting sequential bilateral ocular melanoma in an electric arc welder with 15 years of practice in the profession. The authors associate the patient's predisposition to this type of cancer with his occupational activity. A case-control(5) conducted with a population diagnosed with ocular melanoma revealed that there is an increased risk for this type of cancer in groups exposed to artificial UV at work, as is the case of welders.

Analysis of the mean scores of the remaining systems obtained in the apprentices' before- and aftertest assessments showed an increase in the post-test mean for the cardiac and respiratory systems and a decreased mean for the auditory and gastric systems. Hence, we infer that the intervention enabled the apprentices to identify work-related health disorders.

These results are in agreement with the idea that RC strategies, used during the SENI, enable different groups to identify sources of information and specific knowledge as instruments that protect the health of apprentices and future workers, as well as that of their colleagues. One study conducted with a group of rural workers first identified the perceptions of these workers concerning the risk of pesticides and later reported the implementation of participative workshops as a strategy of RC. It identified that when the individuals' perceptions of risk were incorporated into the RC strategies, a new basis of knowledge concerning work practices was possible through examples and experiences shared based on the knowledge of situations experienced by the workers themselves ${ }^{(24)}$. We also note that when work characteristics, such as the conditions of exposure to the different risks relating to potential organic disorders, are presented, as was the case of the SENI, it enables apprentices to be proactive and protect their own health. Similar studies with welding apprentices were not found.

Correlation between age and the post-test results for the cardiac, gastric, musculoskeletal and respiratory systems indicates that the younger welding apprentices identified more disorders related to these systems than the older ones. We understand that the opportunity to communicate the risks and relate them to organic disorders with the practice of welding, which was enabled by the SENI, was grasped by the younger apprentices. Such a result was also reported in one investigation that sought to explore the impact of online learning from a theoretical training program on electrics and welding, in which younger apprentices presented greater adherence and ease in the program(25).

The younger apprentices' condition of grasping knowledge may be a factor that contributes to this correlation. The older apprentices have alreadyestablished concepts concerning certain subjects, which may lead to a greater difficulty in acquiring knowledge that opposes what is already established. We understand, however, that these are characteristics that may be modified with an intensification and continuity of interaction processes and the exchange of knowledge primarily using RC. Even though the study does not address a representative sample of the population, we believe this fact is minimized since the literature reports the same organic disorders identified by the welding apprentices in this study to be relevant. Therefore, this study contributes to strengthening the theme in the nursing field.

\section{Conclusion}

This study's results show that the apprentices identified the organic disorders related to the practice of welding during the intervention, especially musculoskeletal disorders, since the analysis of the mean scores of the before- and after-test of the musculoskeletal system allowed us to observe the influence of SENI in the apprentices' acquiring knowledge concerning disorders related to this system and the practice of welding.

The analysis of the strength of the relationship between age and health disorders as self-reported by the apprentices before and after the SENI showed a negative correlation between the welding apprentices and the mean scores of all the organic systems. It indicates that the younger the individual, the higher the mean of assessment for organic disorders. Therefore, the sooner interventions are implemented that seek to communicate risks and disorders that may emerge due to the occupational activity are implemented, the better the results. It is believed that RC, through an educational process, can change individual behavior 
because it is a process in which apprentices acquire and multiply knowledge in their work environment and, consequently, has an impact on the collective working conditions. We assert that being aware of the health disorders as self-reported by welding apprentices is fundamental in order for occupational nurses to develop an efficient RC plan as a positive tool of learning and teaching.

\section{References}

1. Modenesi PJ, Marques PV. Soldagem I.[Internet]. Introdução aos Processos de Soldagem. Universidade Federal de Minas Gerais; 2006. [acesso 18 jun 2011]. Disponível em: http://www.demet.ufmg.br/grad/ disciplinas/emt019/processo.pdf

2. Turaka K, Shields CL, Shah CP, Say EA, Shields JA. Bilateral uveal melanoma in an arc welder. Graefes Arch Clin Exp Ophthalmol. 2011;249(1):141-4.

3. Cavallari JC, Fang SC, Dobson CB, Christiani DC. Ventricular arrhythmia events in boilermaker construction workers exposed to metal-rich fine particles. Occup Environ Med. [Internet]. 2007; [acesso 12 dez 2011];64:e31. Disponível em: http://oem.bmj. com/content/64/12/e31.extract

4. Andreassi L. UV exposure as a risk factor for skin cancer. Expert Rev Dermatol. 2011;6(5):445-54.

5. Guénel P, Laforest L, Cyr D, Févotte J, Sabroe S, Dufour

$\mathrm{C}$, et al. Occupational risk factors, ultraviolet radiation, and melanoma: a case-control study in France. Cancer Causes Control. 2001;12(5):451-9.

6. Sorensen AR, Thulstrup AM, Hansen J, Ramlau-Hansen $\mathrm{CH}$, Meersohn A, Bonde JP, et al. Risk of lung cancer according to mild steel and stainless steel welding. Scand J Work Environ Health. 2007;33(5):379-86.

7. Francisco C, Edwin T. Implementation of an ergonomics program for welding department inside a car assembly company. Work. 2012;41:1618-21.

8. Burström L, Hagberg M, Liljeind I, Lundström R, Nilsson $T$, Pettersson $H$, et al. A follow-up study of welders' exposure to vibration in a heavy engineering production workshop. J Low Freq Noise Vib Act Cont. 2010;29(1):33-9.

9. Aragonés N, Pollán M, Gustavsson P. Stomach cancer and occupation in Sweden: 1971-89. Occup Environ Med. 2002;59(5):329-37.

10. Bhumika N, Prabhu GV, Ferreira AM, Kulkarni MK. Noise-induced hearing loss still a problem in shipbuilders: a cross-sectional study in Goa, India. Ann Med Health Sci Res. 2013;3(1):1-6.
11. Guerra MR, Lourenço PMC, Bustamante-Teixeira MT, Alves MJM. Prevalência de perda auditiva induzida por ruído em empresa metalúrgica. Rev Saúde Pública. 2005;39(2):238-44.

12. International Labour Organization. Occupational Safety and Health Act of 16 June 1999. 1999. [acesso 9 ago 2012]. Disponível em: http://www.ilo.org/wcmsp5/ groups/public/---ed_protect/---protrav/---ilo_aids/ documents/legaldocument/wcms_127474.pdf

13. Leonard SS, Chen BT, Stone SG, SchweglerBerry D, Kenyon AJ, Frazer D, et al. Comparison of stainless and mild steel welding fumes in generation of reactive oxygen species. Particle Fibre Toxicol. 2010;7(32):1-13.

14. Cezar-Vaz MR, Soares MCF, Martins SR, Sena J, Santos LR, Rubira LT, et al. Saber Ambiental: instrumento interdisciplinar para a produção de saúde. Texto Contexto Enferm. 2005;14(3):391-7.

15. Almeida MCV, Cezar-Vaz MR, Soares JFS, Silva MRS. The prevalence of musculoskeletal diseases among casual dock workers. Rev. Latino-Am. Enfermagem. 2012;20(2):243-50.

16. Rocha FLR, Marziale MHP, Hong O-S. Work and health conditions of sugar cane workers in Brazil. Rev Esc Enferm USP. 2010;44(4):978-83.

17. Denipotti MEP, Robazzi MLCC. Riscos ocupacionais identificados nos ambientes de panificação brasileiros. Ciênc Enferma. 2011;17(1):117-27.

18. Gube M, Brand P, Schettgen T, Bertram J, Gerards $K$, Reisgen $U$, et al. Experimental exposure of healthy subjects with emissions from a gas metal arc welding process - part II: biomotoring of chromium and nickel. Int Arch Occup Environ Health. 2013;86(1):31-7.

19. Järvelä $M$, Kauppi $P$, Tuomi $T$, Luukkonen $R$, Lindholm $H$, Nieminen $R$, et al. Inflammatory response to acute exposure to welding fumes during the working day. Int J Occup Med Environ Health.2013; 26(2):220-9.

20. U.S. Public Health Service. Risk Communication: Working with Individuals and Communities to Weigh the Odds. Prevention Report. Washington, DC; 1995.

21. Slovic P. The Perception of Risk. London: Earthscan; 2000. 518 p.

22. Coggins MA, Iente EV, Mccallig M, Paddan G, Moore K. Evaluation of Hand-Arm and Whole-Body Vibrations in Construction and Property Management. Ann Occup Hyg. 2010;54(8):904-14.

23. Ministério da Saúde (BR). Doenças relacionadas ao trabalho: manual de procedimentos para os serviços de saúde. Brasília: Ministério da Saúde; 2001. 
24. Peres F, Rodrigues KM, Belo MSSP, Moreira JCM, Claudio L. Design of risk communication strategies based on risk perception among farmers exposed to pesticides in Rio de Janeiro State, Brazil. Am J Ind Med. 2013;56(1):77-89.

25. Burkle M. Apprenticeship students learning on-line: opportunities and challenges for polytechnic institutions.

Comunicar. 2011;37(19):45-53. 